\title{
Factors affecting trematode infection rates in freshwater mussels
}

\author{
Tomasz Müller • Marcin Czarnoleski • \\ Anna Maria Labecka • Anna Cichy • \\ Katarzyna Zając $\cdot$ Dominika Dragosz-Kluska
}

Received: 6 February 2014/Revised: 17 June 2014 / Accepted: 23 June 2014 / Published online: 20 July 2014

(C) The Author(s) 2014. This article is published with open access at Springerlink.com

\begin{abstract}
Mussels are intermediate hosts of digenean trematodes, but determinants of these infections remain unknown. To address this problem, we collected duck mussels Anodonta anatina in eighteen lakes from northeastern Poland and examined how mussel age, sex, and the encrustation with zebra mussels Dreissena polymorpha and environmental conditions in lakes influenced infection rates. We also assessed parasitic preferences to host gonads and hepatopancreas and the impact of parasites on female fertility. Mussels were infected with Rhipidocotyle campanula and Phyllodistomum sp. Infection rates were higher in older and female mussels but were unrelated to the biomass of encrusting $D$. polymorpha and the trophy, thermal conditions, and $\mathrm{Ca}^{2+}$ availability. Parasites occupied gonads more often than
\end{abstract}

Handling editor: Beat Oertli

Electronic supplementary material The online version of this article (doi:10.1007/s10750-014-1965-7) contains supplementary material, which is available to authorized users.

T. Müller $(\bowtie) \cdot$ K. Zając

Institute of Nature Conservation, Polish Academy of

Sciences, Mickiewicza 33, 31-120 Kraków, Poland

e-mail: tomasz.muller@uj.edu.pl

\section{Present Address:}

M. Czarnoleski · A. M. Labecka · D. Dragosz-Kluska Institute of Environmental Sciences, Jagiellonian University, Gronostajowa 7, 30-387 Kraków, Poland e-mail: marcin.czarnoleski@uj.edu.pl hepatopancreas. Infected females were less likely to carry glochidia and incubated fewer glochidia. We suggest that the risk of infection by digenean trematodes increases with the amount of water processed by filter-feeding hosts and/or that parasites actively seek hosts which can provide them with abundant resources. This mechanism explains why parasites more often occupied older and female mussels and targeted their gonads. Future research on trematodemussel interactions should integrate knowledge on different elements of the complex trematode life cycles, including effects of higher-order hosts such as fish.

Keywords Unionidae - Digenea $\cdot$ Glochidia $\cdot$ Life history $\cdot$ Physical environment $\cdot$ Life cycle

\section{Introduction}

Parasitic platyhelminths evolved into three groups characterized by distinct life strategies, namely the

\author{
A. M. Labecka \\ Department of General Zoology, Faculty of Biology, \\ University of Szczecin, Felczaka 3c, 71-415 Szczecin, \\ Poland \\ A. Cichy \\ Department of Invertebrate Zoology, Faculty of Biology \\ and Environment Protection, Nicolaus Copernicus \\ University in Toruń, Lwowska 1, 87-100 Toruń, Poland
}


Monogenea, the Cestoda (tapeworms and allies), and the Trematoda, which include the major group of Digenea and the minor group of Aspidogastrea (Cribb et al., 2001, 2002). Monogeneans are external parasites that lack intermediate hosts and asexual reproduction, and consequently, their infections are restricted to hosts from water environments, mainly bony fishes. The intestinal parasitism of cestodes and trematodes allows them to exploit a wide range of hosts from aquatic and terrestrial environments (Cribb et al., 2002). In contrast to monogeneans, digenean trematodes evolved complex life cycles which typically involve larvae that reproduce asexually in one or more intermediate invertebrate or vertebrate hosts and an adult stage that reproduces sexually in a definite vertebrate host. The asexual reproduction of larvae was postulated to play a major role in the origin of the spectacular diversity of digenean trematodes (Cribb et al., 2001, 2002; Esch et al., 2002; Poulin \& Cribb, 2002).

Transmission via multiple hosts makes digenean trematodes important players in multitrophic interactions (Mouritsen \& Poulin, 2005). Although the role of digenean trematodes in the ecology and evolution of freshwater communities has been addressed by many studies of gastropods (Jokela \& Lively, 1995; Sorensen \& Minchella, 2001; Hechinger \& Lafferty, 2005), interactions between digenean trematodes and their bivalve hosts remain relatively poorly understood. We now know that bivalves are used as intermediate hosts by several families of digenean trematodes (Overstreet \& Curran, 2002; Campbell, 2008; Grizzle \& Brunner, 2009). For example, swan mussels (Anodonta cygnea) serve as the intermediate host of the digenean trematode Phyllodistomum elongatum (Gorgoderidae), and zebra mussels (Dreissena polymorpha) are the intermediate host of Phyllodistomum folium (Orecchia et al., 1975; Laruelle et al., 2002). The life cycle of these parasites is completed in Cyprinidae fishes that serve as definite hosts (Orecchia et al., 1975; Peribanez et al., 2006, 2011). Our study organisms, duck mussels (Anodonta anatina), are the first intermediate host of the digenean trematode Rhipidocotyle campanula (Bucephalidae), which further transmits through the next intermediate host, the common roach (Rutilus rutilus), before entering its definite hosts, either the perch (Perca fluviatilis) or the zander (Stizostedion lucioperca) (Taskinen et al., 1991; Gibson et al., 1992). Fragmentary evidence suggests that digenean trematodes may affect physiology (Jokela et al., 1993), growth (Taskinen, 1998), and reproductive ability (Taskinen \& Valtonen, 1995) of their bivalve hosts. Similarly, aspidogastrean trematodes were observed to negatively impact physiology and growth of their mussel hosts (Gangloff et al., 2008). The selective pressure of digenean trematodes has only occasionally been considered in research on bivalve life history (Haukioja \& Hakala, 1978; Jokela \& Mutikainen, 1995, but see Jokela et al., 2005). Even less is known about the biotic and abiotic factors that determine infection rates in populations of these mollusks.

An understanding of the distribution and biological impacts of digenean trematodes on ecosystems requires consideration of a wide array of conditions that affect the life cycle dynamics of these parasites. Our study aims to identify the factors that shape the abundance of digenean trematodes in duck mussels. We studied duck mussels in eighteen lakes, which differed in their physicochemical conditions and in the intensity with which duck mussels were encrusted by zebra mussels. This large-scale comparative approach allowed us to test our hypotheses in a gradient of environmental conditions. First, we assessed how mussel age, sex, and zebra mussel overgrowth were correlated with infection rates. Infection by free-swimming trematode larvae (miracidium) should be correlated with the volume of water processed by a mussel host (Taskinen \& Valtonen, 1995). We therefore expected to observe an increase in the prevalence of parasites in older mussels. Additionally, given that reproduction imposes more physiological costs on unionid females than on males (Heino \& Kaitala, 1996), we expected higher infection rates in females. We then examined whether parasites occupied the gonads and hepatopancreases of their hosts with equal frequency and what type of damage they caused to the host tissue. We also quantified changes in mussel fertility associated with infections. Finally, we investigated whether environmental conditions in the lakes can explain differences in the abundance of parasites among mussel populations. Earlier studies suggest that parasitism among mussels might attain its highest rates in lentic habitats and nutrient-enriched streams (Humes \& Jamnback, 1950; Fuller, 1974), but there were no studies directly investigating the links between physicochemical parameters and parasitism. Given the scarcity of data, we generally hypothesized that eutrophic waters with low oxygen supply would worsen the physiological 


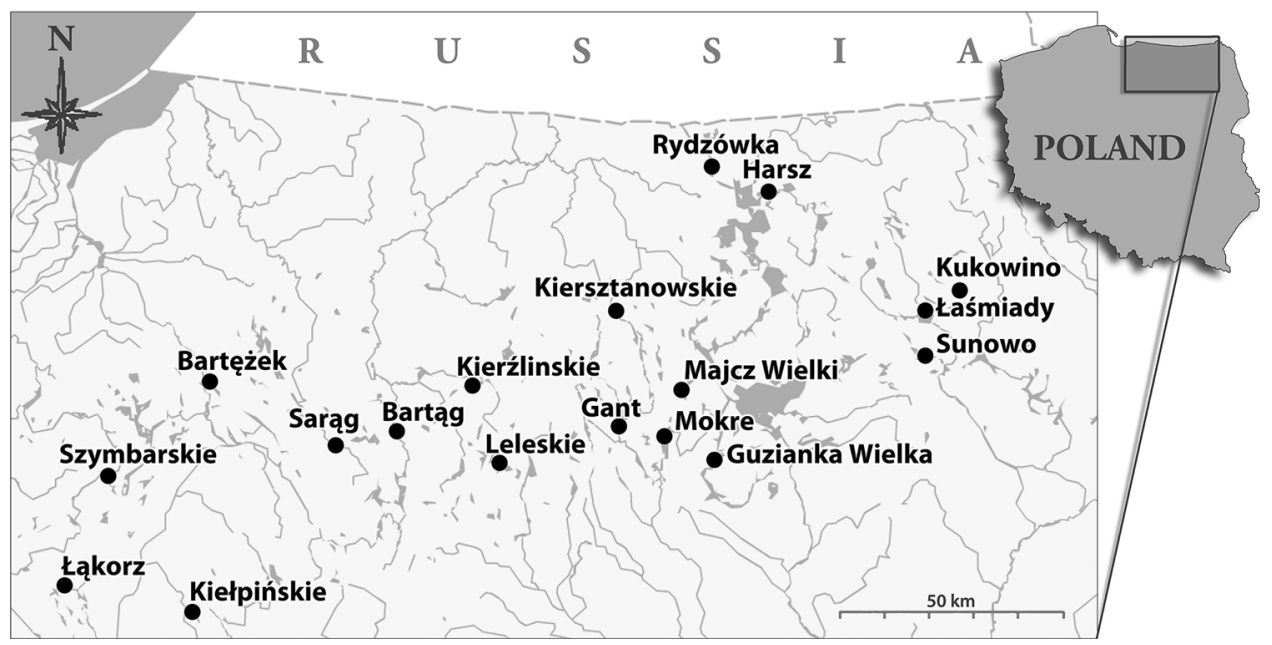

Fig. 1 Duck mussels, A. anatina, were studied in 18 lakes in northeastern Poland: Bartąg (Bg), Bartężek (Bk), Gant (Gt), Guzianka Wielka (Gw), Harsz Wielki (Hw), Kiełpińskie (Kl), Kiersztanowskie (Kr), Kierźlińskie (Kz), Kukowino (Ko),

state of duck mussels and result in an increased susceptibility to infections. Moreover, more productive lakes should support larger populations of fishes, which serve as intermediate and final hosts of digenean trematodes, increasing this way the exposure of duck mussels to infections by miracidia.

\section{Methods}

\section{Abiotic conditions in lakes}

We conducted our study in 18 duck mussel populations from dimictic lakes in northeastern Poland (Fig. 1). Each lake belongs to a separate drainage basin (Jańczak, 1999). We characterized the environmental conditions in these lakes using 15 physicochemical parameters (Table 1). The parameters were measured between 2003 and 2007 during the annual water quality monitoring program of the Regional Inspectorate of Environmental Protection in Olsztyn, Poland (ISO/IEC 17025 standards). To analyze the relationships among the studied environmental parameters and to reduce their number in further statistical analyses, we performed a factor analysis (with biquartimax normalized rotation) on them (Statistica 10, Statsoft, Poland). If necessary, parameters were transformed by natural logarithms prior to the analysis to attain normality (Table 1).
Leleskie (Le), Łąkorz (Lz), Łaśmiady (Ly), Majcz Wielki (Mw), Mokre (Mo), Rydzówka (Ra), Sarąg (Sg), Sunowo (So), and Szymbarskie (Se)

Mussel collection and shell measurements

Approximately, 200 A. anatina mussels were collected in mid-September 2008 and 2009 in the littoral zone of each lake by SCUBA divers and by hand. At this time of the year, glochidia are typically fully developed in females of this bradytictic species (Piechocki, 1969; Haukioja \& Hakala, 1978). The mussels were transported alive to the Hydrobiological Station of the Polish Academy of Sciences in Mikołajki. Encrusting zebra mussels, D. polymorpha, were detached from $A$. anatina shells and weighed to the nearest $0.01 \mathrm{~g}$ on an electronic balance. The shells of A. anatina were separated from the soft body by cutting the anterior and posterior adductor muscles. The length, width, and height of each valve were measured to the nearest $0.01 \mathrm{~mm}$ with a Vernier caliper. The measurements of each dimension were averaged. A geometric threedimensional mean was used as an index of body size (Czarnoleski et al., 2003). Mussel ages were assessed based on the annual ring deposition in each shell according to the methods of Haukioja \& Hakala (1978).

Sex identification

Mussel sex was determined under a light microscope (Eclipse E200, Nikon, Japan) by an examination of gonad fluid. Individuals with oocytes in ovaries were 
Table 1 Two factors were extracted by the factor analysis (biquartimax normalized rotation method) from the data on the physicochemical conditions in 18 Polish lakes (Fig. 1)

\begin{tabular}{|c|c|c|c|}
\hline $\begin{array}{l}\text { Physicochemical } \\
\text { parameters }\end{array}$ & Unit & $\begin{array}{l}\text { Factor } \\
1\end{array}$ & $\begin{array}{l}\text { Factor } \\
2\end{array}$ \\
\hline $\begin{array}{l}\text { Mean oxygen saturation of } \\
\text { hypolimnion }_{\ln }\end{array}$ & {$[\%]$} & -0.68 & 0.09 \\
\hline $\begin{array}{l}\text { Biochemical oxygen } \\
\text { demand }_{\ln } \text { (summer, } \\
\text { surface) }\end{array}$ & {$\left[\mathrm{mgO}_{2} / \mathrm{dm}^{3}\right]$} & 0.51 & 0.04 \\
\hline $\begin{array}{l}\text { Biochemical oxygen } \\
\text { demand }_{\text {ln }} \text { (summer, } \\
\text { bottom) }\end{array}$ & {$\left[\mathrm{mgO}_{2} / \mathrm{dm}^{3}\right]$} & 0.70 & 0.27 \\
\hline $\begin{array}{l}\text { Phosphates }_{\text {In }} \text { (summer, } \\
\text { bottom) }\end{array}$ & {$\left[\mathrm{mgP} / \mathrm{dm}^{3}\right]$} & 0.92 & -0.12 \\
\hline $\begin{array}{l}\text { Total phosphorus } \\
\text { (summer, bottom) }\end{array}$ & {$\left[\mathrm{mgP} / \mathrm{dm}^{3}\right]$} & 0.93 & -0.16 \\
\hline $\begin{array}{l}\text { Total phosphorus }_{\ln } \\
\text { (summer, surface) }\end{array}$ & {$\left[\mathrm{mgP} / \mathrm{dm}^{3}\right]$} & 0.76 & 0.08 \\
\hline $\begin{array}{l}\text { Ammonium nitrogen } \\
\text { (summer, bottom })\end{array}$ & {$\left[\mathrm{mgN} / \mathrm{dm}^{3}\right]$} & 0.82 & -0.33 \\
\hline $\begin{array}{l}\text { Total nitrogen } \\
\text { summer, surface average) }\end{array}$ & {$\left[\mathrm{mgN} / \mathrm{dm}^{3}\right]$} & 0.49 & 0.50 \\
\hline $\begin{array}{l}\text { Chlorophyll }_{\text {ln }} \text { (spring/ } \\
\text { summer, surface average) }\end{array}$ & {$\left[\mathrm{mg} / \mathrm{m}^{3}\right]$} & 0.74 & 0.30 \\
\hline $\begin{array}{l}\text { Secchi disk } \text { ln }_{\text {ln }} \text { (spring, } \\
\text { summer) }\end{array}$ & {$[\mathrm{m}]$} & -0.80 & -0.24 \\
\hline Maximal depth $_{\text {ln }}$ & {$[\mathrm{m}]$} & -0.61 & 0.22 \\
\hline Water quality index & $1.33-3.29$ & 0.87 & 0.24 \\
\hline $\mathrm{Ca}^{2+}$ (spring, surface) & {$\left[\mathrm{mgC} / \mathrm{dm}^{3}\right]$} & -0.27 & 0.77 \\
\hline $\mathrm{pH}$ & $\ln _{10}\left[\mathrm{H}_{3} \mathrm{O}^{+}\right]$ & 0.54 & 0.40 \\
\hline $\begin{array}{l}\text { Temperature (summer, at } \\
\text { 3-m depth) }\end{array}$ & {$\left[\mathrm{C}^{\circ}\right]$} & -0.49 & -0.77 \\
\hline $\begin{array}{l}\text { Proportion of explained } \\
\text { variance }\end{array}$ & & 0.49 & 0.14 \\
\hline
\end{tabular}

The value of the coefficients (factor loadings) reveals the impact of the environmental parameters on the factor values. High values of Factor 1 reflect high eutrophication levels (trophy index). High values of Factor 2 reflect high $\mathrm{Ca}^{2+}$ levels and low water temperatures in the lakes $\left(\mathrm{Ca}^{2+} /\right.$ temperature index)

classified as females, whereas individuals with spermatozoa and/or spermatid morulae in testes were classified as males (Heard, 1975; Kotrla, 1989). Mussels with both oogenetic and spermatogenetic cells were classified as hermaphrodites (van der Schalie, 1970). The sex identification of individuals in the undifferentiated or spawning stage and/or with gonad tissues damaged by trematode larvae was performed with histological methods. Samples of gonads collected from such mussels were fixed in $6 \%$ buffered neutral formalin for 2 weeks and dehydrated in graded ethanol $(70,80,90$, and $96 \%)$ series and a butyl alcohol. After clearing in chloroform, the samples were embedded in paraffin wax. Serial 5- $\mu \mathrm{m}$ thick sections were cut with a motorized rotary microtome (RM 2155, Leica, Germany), stained progressively with Ehrlich's hematoxylin (Carl Roth, Germany), counterstained with water eosin Y (Fluka, Germany), cleared in ST Ultra (Leica), and mounted with CV Ultra (Leica). The gonad cross sections were examined for the presence of oocytes in ovaries and spermatozoa and/or spermatid morulae in testes under a light microscope (Eclipse 80i, Nikon) equipped with a digital camera (Nikon) and NIS Elements analysis software (Nikon).

\section{Glochidia number assessment}

The outer demibranches of mussel gills carrying larvae were cut from the visceral mass and fixed in $70 \%$ ethanol. The assessment of glochidia numberour measure of female fecundity-was performed on mussel subsamples. From each population and each age class, we randomly sampled two gravid females not infected by trematode larvae (in some cases, only 1 female was available), and one gravid female that was infected by trematode larvae (if available). To separate the glochidia from the gill tissue, the outer demibranches were dissected, fragmented with a scalpel, and placed in a plastic beaker filled with $200 \mathrm{ml}$ of tap water. The mixture was then stirred for 7 min with an electric stirrer. Next, the beaker was filled with water up to $1,000 \mathrm{ml}$ and placed on a magnetic stirrer to create a homogenous suspension of glochidia in the water column. Eight $1 \mathrm{ml}$ samples of glochidia suspension were taken with an Acura ${ }^{\circledR} 810$ (Socorex Isba SA, Switzerland) adjustable micropipette placed near the beaker wall, halfway down the water column. The samples were placed in wells of cell culture plates $\left(\mathrm{BD}\right.$ Falcon ${ }^{\mathrm{TM}}$ ) and photographed under a stereoscopic microscope (SZ CTV, Olympus, Japan) equipped with PixeLINK ver. 4.82 camera and Lucia Measurement image software (Lim Laboratory Imaging, Czech Republic). The pictures were used to count glochidia in the samples, and this information was then used to assess the total number of glochidia in the $1,000 \mathrm{ml}$ volume of glochidia suspension, which 
translated into the number of glochidia brooded by an individual female.

Parasitological analyses

Larval stages of digenetic trematodes were examined under a light microscope (Eclipse E200, Nikon) in the gonads and hepatopancreas of dissected mussels. Trematode species were identified on the basis of live cercariae morphology (Orecchia et al., 1975; Baturo, 1977; Richardson, 1990; Taskinen et al., 1991). To determine the damage inflicted on the gonadal tissue by trematode larvae, organs harboring sporocysts and/ or cercariae were fixed in $6 \%$ buffered neutral formalin, and histological slides were prepared following the procedure used in sex identification.

Hypothesis testing

\section{Predictors of infection rates}

All statistical analyses were performed in Statistica 10 (StatSoft, Poland). First, we identified the predictors of infection rates in mussels. We classified mussels as being infected if our histological analyses of gonads and hepatopancreas revealed the presence of trematode larvae in either organ (we did not differentiate between trematode species in this analysis). We examined these data with a generalized linear model (GLM) with a binomial distribution and logit link function. The model considered population and sex as grouping predictors and mussel age (years) and the total mass of overgrowing zebra mussels (our index of overgrowth) as numerical predictors. We excluded hermaphrodites from this analysis. The mass of zebra mussels was transformed by natural logarithms after adding 0.01 because some $A$. anatina were not overgrown by zebra mussels. The infection level estimates for lakes (hereafter the infection level) represent values that would be expected if the lakes were uniform with respect to the sex ratio, age structure, and overgrowth intensity. These values were further used in the analysis of partial correlations to test whether cross-population differences in the infection rates correlated with environmental conditions in the lakes.

Our factor analysis of lake environmental parameters revealed two major factors, which together explained $63 \%$ variance in the environmental data
(Table 1). Factor 1 was primarily determined by parameters closely related to the lake trophic status (hereafter trophy index). Factor 1 was positively correlated with the measures of biochemical oxygen demand, the amount of phosphates and total phosphorous, the amount of ammonium nitrogen, and the chlorophyll concentration and negatively correlated with Secchi disk visibility, maximal lake depth, and hypolimnetic oxygen saturation. Factor 2 was positively correlated with the $\mathrm{Ca}^{2+}$ and negatively correlated with the water temperature (hereafter $\mathrm{Ca}^{2+}$ / temperature index). To test whether conditions captured by the two factors were linked to the infection level in the populations, we performed an analysis of partial correlations between the infection level index and the indices of trophy and $\mathrm{Ca}^{2+} /$ temperature.

\section{Distribution of trematode larvae in organs}

We tested whether trematode larvae preferentially occupied gonads or the hepatopancreas. The analysis involved only infected mussels. Given the scarcity of data on infected mussels, we analyzed the data on both sexes and hermaphrodites pooled together. Based on our histological examination of organs, we assigned each infected mussel with a status value of -1 (parasites in hepatopancreas only), 0 (parasites in gonads and hepatopancreas), or 1 (parasites in gonads only)-hereafter known as the organ infection index. We calculated the mean values of the organ infection index in each population. Using Student's $t$ test, we compared these values against the zero value. Under this scenario, a rejection of the null hypothesis indicates that the infection rates in the populations are biased toward one organ or the other. Retention of the null hypothesis indicates that infections are randomly distributed between the two organs. We first analyzed mussels infected with all trematodes pooled together and then conducted separate analyses on mussels infected with a given trematode.

\section{Effects of infection on glochidia production}

We tested whether the infection with trematode larvae affects the production of glochidia by females. In the first analysis, we used the GLM to examine whether the proportion of females with glochidia differed between the infected and uninfected females. The model considered population and infection status as 
grouping factors and age as a numerical covariate. The second analysis included only females that incubated glochidia. We used the General Linear Model to examine whether glochidia abundance differed between the infected and uninfected females. The model considered populations as a random grouping factor, infection status as a fixed grouping factor, body size index as a numeric covariate, and the interaction between population and the body size index. Note that significance of this interaction would indicate that the scaling between female size and glochidia number differed among populations. Prior to this analysis, the data on glochidia number were transformed with natural logarithms.

\section{Results}

Histological and parasitological analyses

We collected a total of 3,535 mussels (2,111 females, 1,280 males, and 47 hermaphrodites; Online Resource). We did not identify the sex of 97 individuals that had already totally spawned or with gonads which were completely damaged by parasites. In total, $7.5 \%$ of the mussels were infected with trematode larvae. We classified trematodes to the species as Rhipidocotyle campanula or Phyllodistomum sp. (Online Resource). The infection rates ranged from $0.5 \%$ in Lake Rydzówka to $27.0 \%$ in Lake Gant (Online Resource).

The gonads of parasite-free mussels were filled solely with reproductive follicles containing the reproductive cells of the host, whereas infected individuals also had a fraction of follicles housing parasitic larvae at different developmental stages (Fig. 2A, B, D). The majority of male and female gonads of A. anatina were found in the final phase of the reproductive cycle. In males, spermatogenic follicles contained spermatid morulae and/or unspawned spermatozoa (Fig. 2B). In females, the ovaries were filled with degenerating unspawned oocytes (Fig. 2D). In heavily infected hosts, the reproductive follicles almost exclusively contained parasitic larvae (Fig. 2A). Serial cross sections of parasitized follicles revealed digenean trematode larvae in the same developmental stage or in different larval stages, such as germ balls and immature and mature cercariae (Fig. 2A, B, D). Cercariae in a wide range of developmental stages were commonly found within sporocyst lumina and most frequently directly inside the reproductive follicles (when the sporocysts burst open) (Fig. 2B). The wall of the reproductive follicles in infected hosts was thicker than that in healthy individuals due to muscle cells proliferation in the membrane of reproductive follicles (Fig. 2A). Invading hemocytes were also visible in mussel testes and ovaries (Fig. 2C). A few solitary digenean trematode larvae were found between hemocel spaces. The proliferation of parasitic larvae caused substantial damage to vast areas of the host reproductive tissues (Fig. 2A).

\section{Predictors of infection rates}

Our GLM analysis (Table 2) revealed that the infection rate generally increased with mussel age $(P<0.002)$ but was independent of the overgrowth by zebra mussels $(P=0.50)$. Controlling for the effects of mussel age, populations differed with respect to the fraction of infected individuals $(P<0.001$; Fig. 3A), and females were infected more often than males $(P=0.001$; Fig. 3B). The partial correlation analysis revealed that neither the trophy index nor the $\mathrm{Ca}^{2+}$ / temperature index (Table 1) explained the cross-population differences in infection rates $(r=-0.08$, $P=0.74$ and $r=0.26, P=0.30$, respectively).

Distribution of trematode larvae in organs

The mean value of the organ infection index was positive in all three considered types of infection (all trematodes: $0.36, R$. campanula 0.31 , Phyllodistomum sp. 0.32; Fig. 4). Student's $t$ test revealed that the organ infection indices calculated for all infected mussels (238 mussels, including individuals with unidentified trematode species) and for mussels infected with $R$. campanula (159 mussels) were both significantly larger than $0 \quad(t=5.14, \quad \mathrm{df}=17$, $P<0.001$ and $t=4.65$, df $=13, P<0.001$, respectively), indicating that in all infected mussels and in mussels infected with $R$. campanula, the trematode larvae occupied the gonads more frequently than the hepatopancreas. Although the mean value of the organ infection index calculated for the mussels infected with Phyllodistomum sp. (56 mussels) was also positive, its value was not significantly different from $0(t=1.71, \mathrm{df}=12$, and $P=0.11)$. 


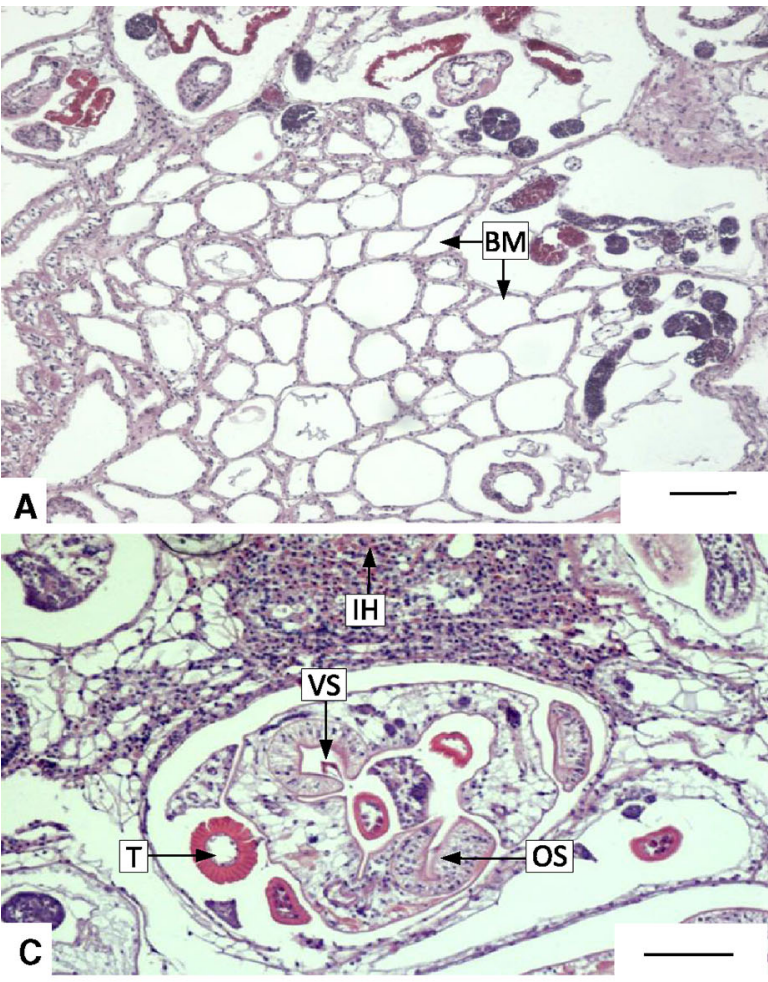

Fig. 2 Damage to the gonads of A. anatina caused by $R$. campanula (A-B) and Phyllodistomum sp. (C-D). A Reproductive follicles of duck mussels with thickened wall in the basement membrane of reproductive follicles (scale bar $100 \mu \mathrm{m})$. B Male follicles with spermatid morulae and unspawned spermatozoa. Follicles contain parasitic larvae in different developmental stages (scale bar $500 \mu \mathrm{m}$ ). C Invading hemocytes in mussel gonads (scale bar $100 \mu \mathrm{m}$ ). D Female

Table 2 Comparison of the infection rate with trematode larvae and the frequency of brooding females in populations of the duck mussel Anodonta anatina (inferential statistics of two Generalized Linear Models)

\begin{tabular}{llrll}
\hline $\begin{array}{l}\text { Dependent } \\
\text { variable }\end{array}$ & Predictor & df & $\begin{array}{l}\text { Wald } \\
\text { statistics }\end{array}$ & $P$ \\
\hline $\begin{array}{l}\text { Infection } \\
\text { with } \\
\text { trematodes }\end{array}$ & Population & 17 & 83.66 & $<0.001$ \\
& Sex & 1 & 10.66 & 0.001 \\
& Age (covariate) & 1 & 11.20 & $<0.002$ \\
& Mass of overgrowing & 1 & 0.46 & 0.50 \\
& $\begin{array}{l}\text { zebra mussels } \\
\text { (covariate) }\end{array}$ & & & \\
$\begin{array}{c}\text { Presence of } \\
\text { glochidia }\end{array}$ & $\begin{array}{l}\text { Population } \\
\text { Infection with }\end{array}$ & 17 & 345.44 & $<0.001$ \\
& trematodes & 146.83 & $<0.001$ \\
& Age (covariate) & 1 & 16.14 & $<0.001$ \\
\hline
\end{tabular}

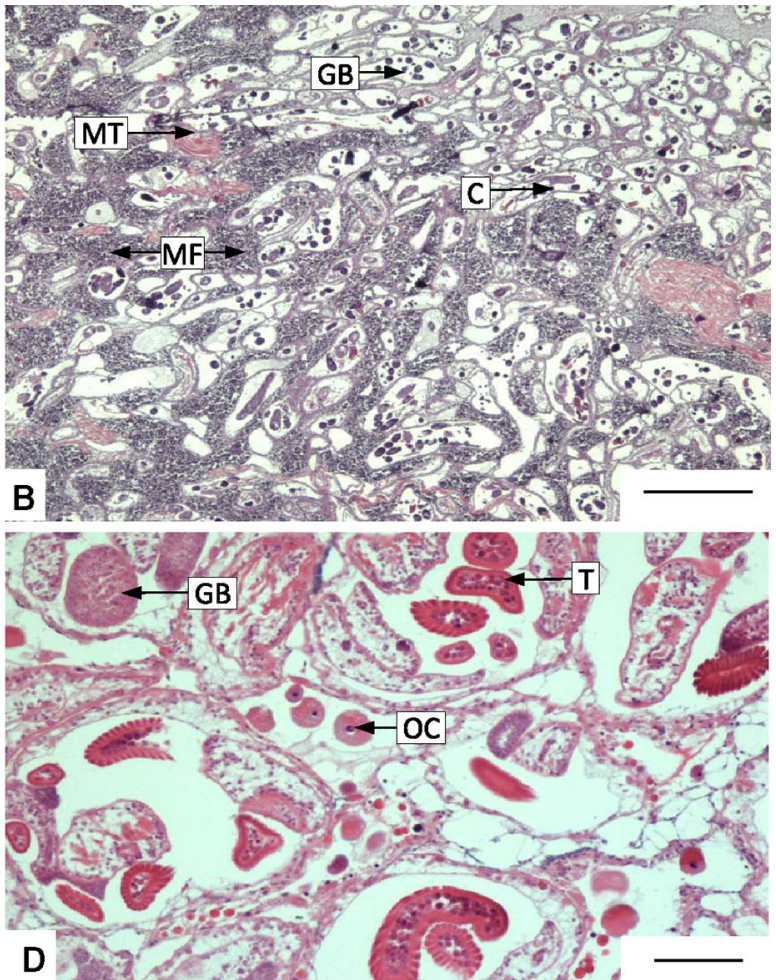

follicles with degenerating unspawned oocytes and with parasitic larvae in different developmental stages (scale bar $100 \mu \mathrm{m}) . B M$ basement membrane of follicle, $C$ cercariae, $G B$ germ balls, $I H$ invading hemocytes, $M F$ male reproductive follicles with sperm and/or spermatid morulae, $M T$ muscle tissue, $O C$ oocytes, $O S$ oral sucker, $T$ tail of cercariae, and $V S$ ventral sucker

Effects of infection on glochidia production

The GLM analysis of the presence of glochidia in females (Table 2) showed that the proportion of females which incubated glochidia increased across age classes $(P<0.001)$. A comparison of mussels at a given age demonstrated that the proportion of females incubating glochidia differed among the populations $(P<0.001$; Fig. 3C) and was significantly higher in the uninfected females $(P<0.001$; Fig. 3D).

The General Linear Model of female fecundity (Table 3) demonstrated that the number of brooded glochidia generally increased with female size $(P<0.001)$. At a given body size, females differed in the number of brooded glochidia among populations $(P<0.001$; Fig. 3E). The size dependence of 
Fig. 3 The proportion of $A$. anatina infected with trematode larvae differed among lakes (A), and females were more heavily infected than males (B). The proportion of brooding females differed among lakes $(\mathbf{C})$, and brooding females were less frequent among mussels infected by trematode larvae (D). The number of glochidia carried by brooding females differed among lakes (E) and infected females brooded fewer glochidia than parasite-free females (for convenience data on glochidia number are shown after reverse transformation from natural logarithms). The mean values $( \pm \mathrm{CI})$ were estimated by statistical models summarized in Table 2 (Fig. 3A-D) and Table 3 (Fig. 3E-F). The lake names are as given in Fig. 1
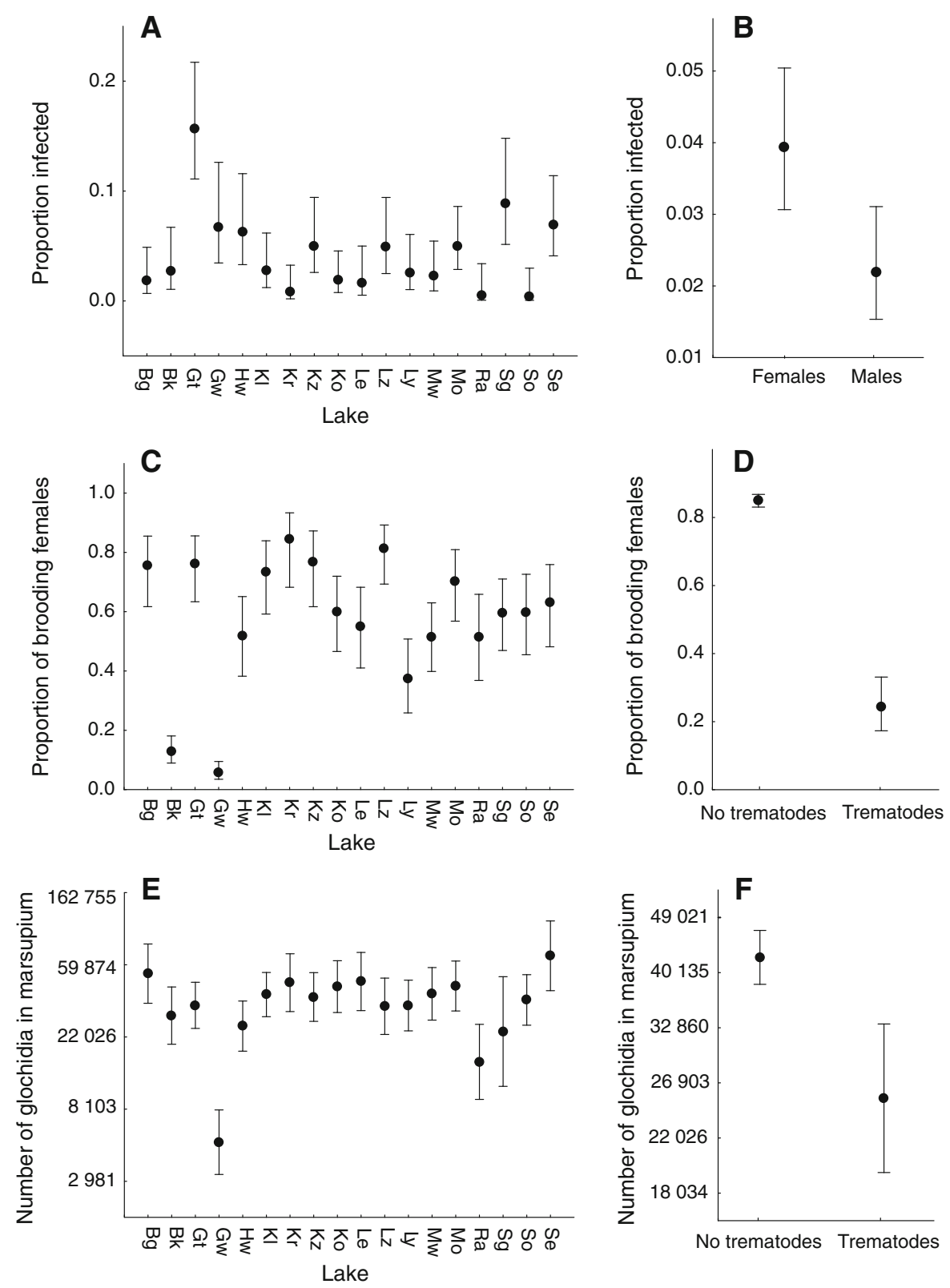

fertility differed among populations, as indicated by the significant interaction between population and body size index $(P<0.001)$. On average, females infected with trematode larvae incubated fewer glochidia than uninfected females $(P<0.001$; Fig. $3 F)$.

\section{Discussion}

The studied populations of duck mussels hosted larvae of digenean trematodes from two genera: Rhipidocotyle and Phyllodistomum. One of the two parasites, $R$. campanula, has been frequently reported in duck mussels (Taskinen \& Valtonen, 1995; Taskinen et al., 1997; Taskinen, 1998) and closely related species (Richardson, 1990), but the larvae of trematodes from the Phyllodistomum genus have only occasionally been found in this species of mussels (Taskinen et al., 1991). Phyllodistomum larvae have been reported in swan mussels A. cygnea (Orecchia et al., 1975), zebra mussels D. polymorpha (Laruelle et al., 2002), and North American unionids (Grizzle \& Brunner, 2009). 


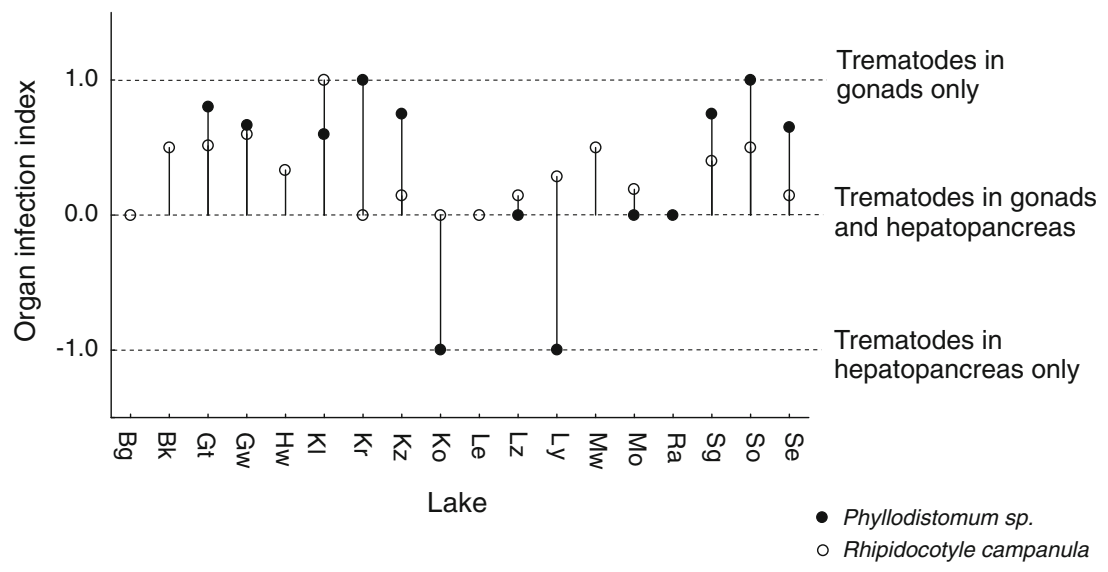

Fig. 4 Larvae of $R$. campanula were more often found in the gonads than in the hepatopancreas of A. anatina, but the larvae of Phyllodistomum sp. were evenly distributed between the two organs. To examine the distribution of trematodes in the organs, infected mussels were assigned an organ infection index: infection only in gonads (1), infection only in hepatopancreas
$(-1)$, and infection in both organs (0). If a trematode occurs randomly in both organs, the mean value of the organ infection index in a population is equal to 0 . If the mean value of the index deviates from 0 , either the gonads (deviation toward 1) or the hepatopancreas (deviation toward -1 ) are more often infected. The lake names are as given in Fig. 1
Table 3 Comparison of the number of glochidia brooded by females in populations of Anodonta anatina mussels (inferential statistics of a General Linear Model)

\begin{tabular}{llrlrl}
\hline Dependent variable & Predictor & df & Effect & $F$ & $P$ \\
\hline Glochidia number & Population & 17 & Random & 3.19 & $<0.001$ \\
& Infection with trematodes & 1 & Fixed & 13.19 & $<0.001$ \\
& Body size index (covariate) & 1 & Fixed & 71.11 & $<0.001$ \\
& Population $\times$ body size index & 17 & Random & 3.10 & $<0.001$ \\
& Error & 222 & & & \\
\hline
\end{tabular}

Our results demonstrated that infections with trematode larvae became more prevalent with increasing mussel age and that female mussels were infected more often than males. Competition for food and oxygen with zebra mussels decreases the energy budgets of overgrown unionids (Patterson, 1997). Therefore, we expected that duck mussels encrusted by zebra mussels would have fewer resources to support immune defense, which should place them at a higher risk of infection. Although we observed that infections with trematodes involved the immunological reactions of hosts, we did not find evidence that overgrown mussels were more prone to infections.

The increased abundance of trematode larvae among older mussels and females was previously observed by Taskinen \& Valtonen (1995) in one population of duck mussels, but detection of the same pattern by our large-scale study suggests that the age and sex dependence of the infection rates may be a widespread phenomenon in duck mussels and in other freshwater mussels and gastropods. Indeed, a link between trematode infections and the age and sex of the hosts has been found in other freshwater bivalves (Rantanen et al., 1998) and in aquatic gastropods (Jokela \& Lively, 1995; Sorensen \& Minchella, 2001; Graham, 2003). In filter-feeding mussels, the increase in the infection rates with age reflects the amount of water processed by the hosts in a lifespan (Taskinen \& Valtonen, 1995). It remains unclear whether differential filtration rates also account for the female-biased infection rates. Alternatively, the female-biased infections may indicate tradeoffs in the allocation to reproduction and antiparasitic defense: offspringbrooding females spend more resources for reproduction than males (Heino \& Kaitala, 1996), which should make females allocate fewer resources to other functions.

Development of trematode larvae likely depends on the amount of resources extracted from their hosts and 
the timespan of infection. Looking from this angle at host-parasite interactions, an alternative class of models postulates that age- and sex-related differences in the infection rates of molluscan hosts reflect the preference of parasites for hosts which provide the best conditions for propagation (Jokela et al., 1993; Guralnick et al., 2004). The physical damage and resource extraction by parasites may negatively affect host longevity and thus the timespan of infection. These adverse effects can be minimized by the exploitation of resources not directly involved in host survival, such as the resources involved in host reproduction. In line with this expectation, we more often observed trematode larvae in the gonads than in the hepatopancreas of duck mussels. Previously, Taskinen et al. (1997) reported that the gonads of duck mussels in two Finnish lakes were more heavily parasitized by $R$. campanula and $R$. fennica than other organs, and Jokela et al. (1993) directly demonstrated that $R$. fennica primarily used the glycogen reserves of duck mussels stored for reproduction. Apparently, larval trematodes maximize their own fitness through preferences for hosts with the highest levels of resource allocation to reproduction. In indeterminately growing hosts such as many mollusks, the allocation of resources to reproduction increases with age and size (Czarnoleski \& Kozlowski, 1998) and is higher in females (Heino \& Kaitala, 1996).

Digenean trematodes are typically viewed as complete castrators of molluscan hosts (Kuris, 1974). Our histological analysis of duck mussels documented various levels of damage to the male and female reproductive organs caused by trematode larvae, though some infected mussels were still ready for reproduction and possessed reproductive cells in their gonads. The structural damage of gonads coupled with energetic costs of infections should negatively impact offspring production of the hosts, which explains why we observed fewer broods and glochidia among the infected females. These findings agree with earlier reports that the larvae of digenean trematodes reduced fecundity of duck mussels (Taskinen et al., 1997), other freshwater mussels (Rantanen et al., 1998) and gastropods (Sorensen \& Minchella, 2001).

Taken together, our results suggest that the pressure exerted by digenean trematode larvae can significantly affect the reproductive output of duck mussels. The next important question is what factors differentiate the strength of this pressure among populations of hosts. Thus far, we have demonstrated that host age and sex play a role in the infections, but apparently, these processes alone cannot account for the crosspopulation differences in the infection rates of duck mussels. We hypothesize that lake-specific environmental conditions may explain cross-population differences in the infection rates, but parameters related to lake trophy, thermal conditions, or $\mathrm{Ca}^{2+}$ availability did not appear to be good predictors of the infection rates in the studied populations of duck mussels. This finding was surprising because lake trophy should influence the abundance of fishes that are used by Rhipidocotyle and Phyllodistomum trematodes as higher-order hosts. Moreover, our analysis involved major environmental determinants of the energy budgets of mussels (Czarnoleski et al., 2010), which should affect resistance to parasitic infections. High values of our trophy index and low values of our $\mathrm{Ca}^{2+}$ / temperature index indicate lower supplies of oxygen and higher metabolic demands associated with the thermal sensitivity of physiology and costliness of shell formation. In addition, thermal conditions should directly affect the risk of encountering miracidia through the thermal dependence of filtration rates. Our results also contrast with the findings of experiments which demonstrated that the exposure of duck mussels to extreme environmental conditions (anoxic stress) in the laboratory increased their susceptibility to infections by copepods (Saarinen \& Taskinen, 2005) and the virulence of trematode infections (Jokela et al., 2005).

\section{Conclusion}

The results of this study suggest that the trematodes Rhipidocotyle campanula and Phyllodistomum sp. play a significant role in freshwater communities by affecting the reproductive success of their intermediate hosts-duck mussels. Although our results demonstrated that the pressure posed by digenean trematode larvae is tightly linked to the age and sex of their hosts, a significant portion of the variation in the infection rates remained unexplained. Quite unexpectedly, environmental factors that affect the mussels' energy budgets and the abundance of higherorder hosts of digenean trematodes failed to explain this variance. A fuller understanding of the role digenean trematodes play in freshwater communities 
may require the integration of information about all factors that affect the dynamics of parasite life cycles, including their demographic processes in intermediate and final hosts. Our knowledge of the interactions between unionidae mussels and their digenean trematode parasites may help protect these imperiled mollusks.

Acknowledgements The study was supported by the Polish Ministry of Scientific Research and Information Technology (Grant \#N N 3041176 33) and Jagiellonian University (DS/ WBiNoZ/INoŚ/757/10). K. Adamus-Fiszer, M. Bednarz, N. Błaszczyk, M. Buczyński, P. Buglewicz, R. Czerniawski, E. Gurda, P. Kubajak, P. Mączka, K. Momot, B. Oleszko, A. Terelis, M. Sitarski, and T. Zając helped with the data collection and logistics. We offer special thanks to T. Zając for valuable suggestions on the study design. We thank J. Kozłowski and E. Zbikowska for their comments on earlier versions of the manuscript. We are grateful to three anonymous reviewers for their suggestions to improve our manuscript.

Open Access This article is distributed under the terms of the Creative Commons Attribution License which permits any use, distribution, and reproduction in any medium, provided the original author(s) and the source are credited.

\section{References}

Baturo, B., 1977. Bucephalus polymorphus Baer, 1827 and Rhipidocotyle illense (Ziegler, 1883) (Trematoda, Bucephalidae): morphology and biology of developmental stages. Acta Parasitologica Polonica 24: 203-220.

Campbell, R. A., 2008. Family Gorgoderide Loos, 1899. In Bray, R. A., D. I. Gibson \& A. Jones (eds), Keys to the Trematoda, Vol. 3. CABI Publishing, Wallingford: 191-214.

Cribb, T. H., R. A. Bray \& D. T. J. Littlewood, 2001. The nature and evolution of the association among digeneans, molluscs and fishes. International Journal for Parasitology 31 : 997-1011.

Cribb, T. H., L. A. Chisholm \& R. A. Bray, 2002. Diversity in the Monogenea and Digenea: does lifestyle matter? International Journal for Parasitology 32: 321-328.

Czarnoleski, M. \& J. Kozlowski, 1998. Do Bertalanffy's growth curves result from optimal resource allocation? Ecology Letters 1: 5-7.

Czarnoleski, M., J. Kozlowski, A. Stańczykowska \& K. Lewandowski, 2003. Optimal resource allocation explains growth curve diversity in zebra mussels. Evolutionary Ecology Research 5: 571-587.

Czarnoleski, M., J. Kozlowski, K. Lewandowski, T. Müller \& A. Stańczykowska, 2010. An evolutionary perspective on the geographic and temporal variability of life histories in European zebra mussels. In Van der Velde, G., S.
Rajagopal \& A. Bij de Vaate (eds), The Zebra Mussel in Europe. Backhuys Publishers, Leiden: 169-182.

Esch, G. W., M. A. Barger \& K. Joel Fellis, 2002. The transmission of digenetic trematodes: style, elegance, complexity. Integrative and Comparative Biology 42: 304-312.

Fuller, S. L. H., 1974. Clams and mussels (Mollusca: Bivalvia). In Hart Jr, C. W. \& S. L. H. Fuller (eds), Pollution Ecology of Freshwater Invertebrates. Academic Press, New York: 215-273.

Gangloff, M. M., K. K. Lenertz \& J. W. Feminella, 2008. Parasitic mite and trematode abundance are associated with reduced reproductive output and physiological condition of freshwater mussels. Hydrobiologia 610: 25-31.

Gibson, D. I., J. Taskinen \& E. T. Valtonen, 1992. Studies on bucephalid digeneans parasitising molluscs and fishes in Finland. II. The description of Rhipidocotyle fennica $\mathrm{n}$. sp. and its discrimination by principal component analysis. Systematic Parasitology 23: 67-79.

Graham, A. L., 2003. Effects of snail size and age on the prevalence and intensity of avian Schistosome infection: relating laboratory to field studies. The Journal of Parasitology 89: 458-463.

Grizzle, J. M. \& C. J. Brunner, 2009. Infectious diseases of freshwater mussels and other freshwater bivalve mollusks. Reviews in Fisheries Science 17: 425-467.

Guralnick, R., E. Hall \& S. Perkins, 2004. A comparative approach to understanding causes and consequences of Mollusc-Digenean size relationships: a case study with allocreadiid trematodes and Cyclocalyx clams. Journal of Parasitology 90: 1253-1262.

Haukioja, E. \& T. Hakala, 1978. Life-history evolution in Anodonta piscinalis (Mollusca, Pelecypoda) - correlation of parameters. Oecologia 35: 253-266.

Heard, W. H., 1975. Sexuality and other aspects of reproduction in Anodonta (Pelecypoda: Unionidae). Malacologia 15: 81-103.

Hechinger, R. F. \& K. D. Lafferty, 2005. Host diversity begets parasite diversity: bird final hosts and trematodes in snail intermediate hosts. Proceedings of the Royal Society B 272: 1059-1066.

Heino, M. \& V. Kaitala, 1996. Optimal resource allocation between growth and reproduction in clams: why does indeterminate growth exist? Functional Ecology 10: 245-251.

Humes, A. G. \& H. A. Jamnback, 1950. Najadicola ingens (Koenike), a water-mite parasitic in fresh-water clams. Psyche 57: 77-87.

Jańczak, J., 1999. Atlas jezior Polski. Bogucki Wydawnictwo Naukowe S.C., Poznań.

Jokela, J. \& C. M. Lively, 1995. Spatial variation in infection by digenetic trematodes in a population of freshwater snails (Potamopyrgus antipodarum). Oecologia 103: 509-517.

Jokela, J. \& P. Mutikainen, 1995. Phenotypic plasticity and priority rules for energy allocation in a freshwater clam: a field experiment. Oecologia 104: 122-132.

Jokela, J., L. Uotila \& J. Taskinen, 1993. Effects of the castrating trematode parasite Rhipidocotyle fennica on energy allocation of fresh-water clam Anodonta piscinalis. Functional Ecology 7: 332-338.

Jokela, J., J. Taskinen, P. Mutikainen \& K. Kopp, 2005. Virulence of parasites in hosts under environmental stress: 
experiments with anoxia and starvation. Oikos 108: 156-164.

Kotrla, M. B., 1989. Evidence suggestive of ameiotic spermatogenesis in unionid bivalves. American Zoologist 29: 148A.

Kuris, A. M., 1974. Trophic interactions: similarity of parasitic castrators to parasitoids. The Quarterly Review of Biology 49: 129-148.

Laruelle, F., D. P. Molloy \& V. A. Roitman, 2002. Histological analysis of trematodes in Dreissena polymorpha: their location, pathogenicity, and distinguishing morphological characteristics. Journal of Parasitology 88: 856-863.

Mouritsen, K. N. \& R. Poulin, 2005. Parasites boosts biodiversity and changes animal community structure by traitmediated indirect effects. Oikos 108: 344-350.

Orecchia, P. L., L. Paggi, L. Castagnolo, G. Della Seta \& R. Minervini, 1975. Experimental research on the biological cycle of Phyllodistomum elongatum Nybelin, 1926 (Digenea: Gorgoderidae Looss, 1901). Parasitologia 17: 95-101.

Overstreet, R. M. \& S. S. Curran, 2002. Superfamily Bucephaloidea Poche, 1907. In Gibson, D. I., A. Jones \& R. A. Bray (eds), Keys to the Trematoda, Vol. 1. CABI Publishing, Wallingford: 67-110.

Patterson, M. A., 1997. Effects of quarantine times on glycogen levels of native freshwater mussels (Bivalvia: Unionidae) previously infested with zebra mussels. American Malacological Bulletin 14: 75-79.

Peribanez, M. A., M. L. Elrio, M. J. Gracia, et al., 2006. Phyllodistomum folium (Trematoda: Gorgoderidae) infecting zebra mussels (Dreissena polymorpha) in the Ebro River, Spain. Parasitology International 55(2): 143-145.

Peribanez, M. A., L. Ordovas, J. Benito, et al., 2011. Prevalence and sequence comparison of Phyllodistomum folium from zebra mussel and from freshwater fish in the Ebro River. Parasitology International 60(1): 59-63.

Piechocki, A., 1969. Obserwacje biologiczne nad małżami z rodziny Unionidae w rzece Grabi. Acta Hydrobiologica 11(1): 57-67.
Poulin, R. \& T. H. Cribb, 2002. Trematode life cycles: short is sweet? Trends in Parasitology 18: 176-183.

Rantanen, J. T., E. T. Valtonen \& I. J. Holopainen, 1998. Digenean parasites of the bivalve mollusc Pisidium amnicum in a small river in eastern Finland. Diseases of Aquatic Organisms 33: 201-208.

Richardson, S. D., 1990. Studies on the life-cycle of the digenetic trematode Rhipidocotyle campanula (Dujardin, 1845) (Gasterostomata: bucephalidae) with particular reference to the larval stages. PhD thesis, University of Leeds.

Saarinen, M. \& J. Taskinen, 2005. Long-lasting effect of stress on susceptibility of a freshwater clam to copepod parasitism. Parasitology 130: 523-529.

Taskinen, J., 1998. Influence of trematode parasitism on the growth of a bivalve host in the field. International Journal for Parasitology 28: 599-602.

Taskinen, J. \& E. T. Valtonen, 1995. Age-, size-, and sex-specific infection of Anodonta piscinalis (Bivalvia: Unionidae) with Rhipidocotyle fennica (Digenea: Bucephalidae) and its influence on host reproduction. Canadian Journal of Zoology 73: 887-897.

Taskinen, J., E. T. Valtonen \& D. I. Gibson, 1991. Studies on bucephalid digeneas parasiting molluscs and fishes in Finland: I. Ecological data and experimental studies. Systematic Parasitology 19(2): 81-94.

Sorensen, R. E. \& D. J. Minchella, 2001. Snail-trematode life history interactions: past trends and future directions. Parasitology 123: S3-S18.

Taskinen, J., T. Mäkelä \& E. T. Valtonen, 1997. Exploitation of Anodonta piscinalis (Bivalvia) by trematodes: parasites tactics and host longevity. Annales Zoologici Fennici 34: $37-46$.

van der Schalie, H., 1970. Hermaphroditism among North American freshwater mussels. Malacologia 10(1): 93-112. 